\title{
Time Simulator in Virtual Reality for Children with Attention Deficit Hyperactivity Disorder
}

\author{
Pongpanote Gongsook \\ Eindhoven University of Technology, Eindhoven, The Netherlands \\ p.gongsook@tue.nl
}

\begin{abstract}
This project aims at investigating how effective virtual reality is in manipulating and eventually training time perception for children with learning and/or behavior disorders. The interconnectivity of multiple brain regions is needed for time perception. Small dysfunctions in these brain regions may cause time perceiving problems. Likewise, children with attention deficit hyperactivity disorder (ADHD) appear to have comparable dysfunction in time orientation. However, the time perception can be trained in their early ages. In addition, research confirms the effectiveness of virtual reality in improving the sequential time perception of children with mental retardation. This paper presents the theoretical and empirical framework that uses a virtual reality time simulation game for training time perception of children with ADHD.
\end{abstract}

Keywords. Time Perception, Virtual Reality, Game, Attention Deficit Hyperactivity Disorder, Learning Disorders.

\section{Introduction}

Time is something humans cannot directly perceive with their senses. However, it can be perceived by reasoning on one's surrounding context or the sequence of events that happen within one's local environment $[1,2]$. Children as young as 3 year old start developing their sensitivity to duration, and their time perception develops with age [3]. Time perception is a conceptual understanding that enables one's ability to predict, anticipate, and respond to events as past or present occurring in the environment $[1,2]$. Children with attention deficit hyperactivity disorder (ADHD) have shown their difficulties in processing, reading, and telling time [4]. Although there are quizzes and tests on the internet that aim to improve children's time reading [5], most of them are designed for normal children. We aim at a virtual reality game that creates a time simulator for children with learning disorders and ADHD.

\section{Connectivity between Time, Brain Functions and ADHD}

Time perception needs the interconnectivity between multiple brain regions, including the cerebellum, basal ganglia, and prefrontal cortex. Individuals with cerebellar dysfunction may have difficulty with an event that requires precise movement timing 
$[6,7]$. The basal ganglia, prefrontal cortex, and posterior parietal cortex have been suggested to be involved in interval timing [4].

The mentioned brain regions are found to be involved in the dysfunction of time perception during cognitive testing in the ADHDs [8]. ADHD is a behavioral condition identified by DSM-IV [9], which symptoms must be present before the age of seven, persist for at least six months, and be sufficiently severe to impact daily functioning across several settings such as home, school and interpersonal relationships. Children with ADHD have significantly smaller cerebral and cerebellar volumes, particularly the right cerebellum [6]. Besides, there are significantly lower levels of activation in the basal ganglia in children with ADHD [4]. However, rehabilitation as well as training could be done while they are in the early developmental stages [10].

\section{Virtual Reality as a Diagnostic/Training Game}

Virtual reality (VR) can be used in many aspects and application areas. VR simulations allow children with certain impairments to experience what could be difficult or even impossible for them to do in reality [11]. Fairley suggested that patients would feel more amused when they are rehabilitated using games that utilize VR [12]. Riva, Mantovani, and Gaggioli show that knowledge obtained in VR can be transferred into a real environment [13]. It is shown that participants who performed cognitive tasks that targeted on attention performance using VR did outperform scores of those who used the traditional methods [14]. However, we have found no existing effort in training time perception using a Game in Virtual Reality Environments (GVR).

\section{$4 \quad$ Project Approaches}

We aim at GVRs that children with ADHD can play in, and at the same time offers opportunities to train and improve their time perception. Gaming is chosen because it can immediately give them rewards, which they attract to [15]. GVR aims at improving the working memory of children with ADHD, which found out as one of their core cognitive deficits [16]. Improving the working memory might reduce some of their symptoms and associated behavior problems [17]. Mnemonic strategy, which encoding the information in a way other than directly remembering, will be used in this project [18].

The GVR uses linear storytelling so we can ensure that all the children experience the same branch of decisions. It includes mini games for specific memory tests for time estimation, production and reproduction. The game trains the children's time perception using various time teaching techniques such as clock faces or the appearance of the sky at different times of the day. It uses game-world time while teaching and uses real-world time while testing [19]. Before GVR is used as a psychological assessment tool, it must be evaluated by psychologists. 


\section{Conclusion}

The goal is to investigate how effective time simulation in virtual reality is for children with learning disorders. Children with ADHD have time perception problems. However, their symptoms can be cured in their early ages. We believe that children with ADHD will have some benefits from learning time perception via GVR. The time simulator in virtual reality can be a candidate for the solution.

Acknowledgement. This work was supported in part by the Erasmus Mundus Joint Doctorate in Interactive and Cognitive Environments (ICE), which is funded by the EACEA Agency of the European Commission under EMJD ICE FPA n 2010-0012. We are also very grateful for the collaboration with Dr. Jos Hendriksen from Kempenhaeghe- centre for neurological learning disabilities.

\section{References}

1. Le Poidevin, R.: The Experience and Perception of Time, http://plato.stanford. edu/archives/fall2011/entries/time-experience/

2. Time Perception, http://www.britannica.com/EBchecked/topic/ 596177 / time-perception

3. Droit-Volet, S.: Alerting attention and time perception in children. J. Exp. Child Psychol. 85, 372-384 (2003)

4. Hurks, P.P., Hendriksen, J.G.: Retrospective and prospective time deficits in childhood ADHD: The effects of task modality, duration, and symptom dimensions. Child Neuropsychol. 17, 34-50 (2011)

5. Learn to Tell Time Games \& Websites for Kids, http://www. learningreviews . com/Telling-Time-Websites-Games-for-Kids .html

6. Toplak, M.E., Dockstader, C., Tannock, R.: Temporal information processing in ADHD: Findings to date and new methods. J. Neurosci. Methods 151, 15-29 (2006)

7. Casini, L., Ivry, R.B.: Effects of divided attention on temporal processing in patients with lesions of the cerebellum or frontal lobe. Neuropsychology 13, 10-21 (1999)

8. Smith, A., Taylor, E., Rogers, J.W., Newman, S., Rubia, K.: Evidence for a pure time perception deficit in children with ADHD. J. Child Psychol. Psychiatry 43, 529-542 (2002)

9. DSM-IV-R: Statistical Manual of Mental Disorders, Text Revision (DSM IV-R). Arlington, VA (2000)

10. Barkley, R.A., Koplowitz, S., Anderson, T., McMurray, M.B.: Sense of time in children with ADHD: effects of duration, distraction, and stimulant medication. J. Int. Neuropsychol. Soc. 3, 359-369 (1997)

11. Rose, F.D., Attree, E.A., Brooks, B.M., Andrews, T.K.: Learning and memory in virtual environments: a role in neurorehabilitation? Questions (and occasional answers) from the University of East London. Presence 10, 345-358 (2001)

12. Fairley, M.: Fun and Games: Virtual Reality Turns the Work of Rehab into Play, http: / /www. oandp.com/articles/2010-05_01.asp

13. Riva, G., Mantovani, F., Gaggioli, A.: Presence and rehabilitation: toward secondgeneration virtual reality applications in neuropsychology. J. Neuroeng. Rehabil. 1, 9 (2004) 
14. Parsons, T.D., Bowerly, T., Buckwalter, J.G., Rizzo, A.A.: A controlled clinical comparison of attention performance in children with ADHD in a virtual reality classroom compared to standard neuropsychological methods. Child Neuropsychol. 13, 363-381 (2007)

15. Bioulac, S.S., Arfi, L., Bouvard, M.P.: Attention deficit/hyperactivity disorder and video games: A comparative study of hyperactive and control children. Eur. Psychiatry 23, 134$141(2008)$

16. Dehn, M.J.: Working Memory and Academic Learning Assessment and Intervention. Wiley (2008)

17. Klingberg, T., Forssberg, H., Westerberg, H.: Training of working memory in children with ADHD. J. Clin Exp. Neuropsychol. 24, 781-791 (2002)

18. Mastropieri, M.A.: Enhancing School Success with Mnemonic Strategies. Interv. Sch. Clin. 33, 201-208 (1998)

19. Zagal, J.: Temporal frames: a unifying framework for the analysis of game temporality. DiGRA, 1-8 (2007) 